\title{
«Chè per tal variar natura è bella»: variaciones cervantinas sobre el tópico de la navegación amorosa
}

\author{
SARA SANTA-AgUILAR*
}

\begin{abstract}
Resumen
En los estudios del tópico de la navegación amorosa, la poesía de Cervantes se menciona o por el romance de don Luis inserto en el Quijote o por el soneto del enamorado portugués inserto en el Persiles. Sin embargo, se trata de un motivo muy recurrente en la poesía inserta del alcalaíno. Pero más allá del aspecto cuantitativo, la importancia de Cervantes para los estudios del tópico reside en que no se limita a repetir unas metáforas cristalizadas por la tradición, sino que las transforma. Desde el proceso mismo de inserción, el motivo se recontextualiza a la luz de las historias de sus autores ficcionales, pero, además, varios de estos poetas ficcionales llevan a cabo diferentes variaciones y giros novedosos sobre el motivo, ampliando los límites expresivos de la tradición que heredan. El propósito del presente artículo es llevar a cabo un estudio detallado del tópico en la poesía inserta de Cervantes, encuadrándola en las coordenadas de la tradición petrarquista -italiana y española- de la que parte para destacar sus innovaciones poéticas en la apropiación del motivo.
\end{abstract}

Palabras clave: Petrarquismo; poesía inserta de Cervantes; navegación amorosa.

Title: "Chè per tal variar natura è bella»: Cervantine Variations on the Topic of Love Seafaring

\begin{abstract}
In the studies about the topic of love seafaring, Cervantes' poetry is only mentioned for the 'romance' by don Luis inserted in Don Quixote or for the sonnet by the enamoured Portuguese inserted in the Persiles. Nevertheless, it is a very recurrent topic in the inserted poetry of the alcalaino. However, beyond the quantitative aspect, the importance of Cervantes for the studies about the topic lies in the fact that he does not simply repeat the metaphors crystallized by the tradition, but he transforms them. From the insertion process

* Universidad de La Rioja. sara-isabel.santa@unirioja.es / ORCID iD: https://orcid.org/00000002-3199-6504
\end{abstract}


itself, the topic is recontextualized in the light of the stories of its fictional authors, but also, several of them carry out different variations and innovative twists in the use of the topic, broadening the expressive limits of the tradition they inherited. The purpose of this article is to carry out a detailed analysis of the topic in Cervantes' inserted poetry, framing it in the coordinates of the Petrarchan tradition -Italian and Spanish- from where it starts to determine his poetical innovations regarding the use of the topic.

Keywords: Petrarchism; Cervantes' Inserted Poetry; Love Seafaring.

\section{Cómo citar este artículo / Citation}

Santa-Aguilar, Sara. 2021. "'Chè per tal variar natura è bella': variaciones cervantinas sobre el tópico de la navegación amorosa». Anales Cervantinos 53: 239-261. https://doi.org/10.3989/anacervantinos.2021.010

A la memoria de mi padre, mi puerto intelectual, mi faro, mi lucero

Bien sabido es que la travesía de Cervantes como poeta por la tradición crítica no ha gozado precisamente de buena estrella. Desde la Vida de Cervantes de Fernández de Navarrete, que acompañó la edición del Quijote de 1819 de la Real Academia Española, empezaron a hacerse tópicas ideas como la de 'la gracia que no quiso darle el cielo' al alcalaíno en materia de poesía. No obstante, contra la corriente de los que Ricardo Rojas acertadamente llamó los «rapsodas de Navarrete» $(1948,33)$, el estudioso argentino y posteriormente José Manuel Blecua ${ }^{1}$ alzaron las velas para una revisión y revaloración que solo en las últimas décadas -salvados los escollos de las condescendientes reivindicaciones románticas de la primera mitad y casi toda la segunda del siglo $\mathrm{XX}^{2}$ - ha empezado a ir a buen viento ${ }^{3}$.

No es de extrañar entonces que, en los estudios sobre el tópico de la navegación amorosa en los Siglos de Oro, de la poesía de Cervantes solo se mencione el romance de don Luis inserto en el Quijote o el soneto del enamorado portugués inserto en el Persiles. Sin embargo, tal como han señalado estudiosos como Ignacio Arellano (1998; 2004) o Carlos Mata (2007), se trata de un motivo recurrente en la lírica del alcalaíno: solo en la poesía in-

1. Contra la lectura seria de Fernández de Navarrete del archicitado terceto del Viaje del Parnaso, Rojas (1948) y posteriormente Blecua (1970) resaltan el carácter lúdico de la obra y llevan a cabo recolecciones pioneras de los versos de esta que van en contravía del terceto citado.

2. Ver Menéndez Pelayo (1941, 268), Gerardo Diego (1948), Luis Cernuda (1964, 45-46) o Vicente Gaos (1979). Las he llamado «reivindicaciones románticas condescendientes» en tanto que desarrollan la idea de raigambre romántica según la cual el 'genio' de Cervantes no cabía en el límite formal del verso -razón por la que aducen su limitada calidad- aunque sostienen que, en cuanto obra de Cervantes, sus poesías no dejan de translucir su 'espíritu'.

3. De particular importancia para un nuevo enfoque de la poesía cervantina en su contexto narrativo resultan los aportes teóricos de Ruiz Pérez (1997), Alcalá-Galán (1999), Romo Feito (2001; 2011; 2012), Montero Reguera (2013) o Matas Caballero (2016), y para una revaloración moderna de sus méritos per se Olay Valdés (2013). 
serta en la narrativa contamos con diecisiete composiciones en las que aparece el tópico, siete de las cuales se dedican exclusivamente al tema ${ }^{4}$.

Pero no se trata solamente de un interés cuantitativo. La importancia de este corpus reside en que no es un ejemplo más de repetición de un motivo cristalizado por la tradición. Cervantes en estas apropiaciones transforma el tópico, altera las relaciones metafóricas preestablecidas desde los contextos específicos a los que se refieren sus autores ficcionales.

Como explica Mercedes Alcalá-Galán en su «Teoría de la poesía en Cervantes», la poesía inserta en un contexto narrativo, «citada», implica un proceso semántico en el que:

El contexto articula el sentido del discurso ajeno, de la cita; une y funde el sentido particular y fragmentario del discurso citado con su sentido último. El contexto crea para la cita un horizonte amplificador, posibilita todas las condiciones de su existencia en la obra literaria, y además participa de la cita desde dentro, contagiándole su naturaleza y creando un tejido nuevo de ecos, claves, reflejos, y reverberaciones de sentido. Pero también el contexto tiene la capacidad por su naturaleza de discurso citante, de resonar a la vez desde dentro de la cita y desde sus márgenes (1999, 32-33).

El tópico de la navegación amorosa en los poemas insertos pasa a través del proceso descrito por Alcalá-Galán. Las metáforas que conforman sus submotivos se vacían de su contenido tradicional. Su abstracción pasa a ser sustituida por los detalles particulares de las historias de sus autores ficcionales, que en el contexto narrativo son el término de realidad detrás de los tropos, lo que «resuena desde adentro». Sin embargo, la transformación del tópico no se da exclusivamente a través de su recontextualización en una situación particular -un fenómeno solo perceptible para los lectores o personajes que ponen en relación el contexto y el poema, la prosa y el verso-. Estos autores ficcionales como poetas $-\mathrm{y}$ en esto reside su importancia para los estudios del tópico- en varias ocasiones llevan a cabo una transformación

4. Estas son: los sonetos de Elicio (VI, 627), Erastro (V, 517), Timbrio (V, 520) y Silerio (V, 521) en La Galatea, el romance de don Luis en el Quijote (I, 43, 446-447) y el soneto del enamorado portugués en el Persiles (I, 9, 196). En este estudio, además de las seis composiciones mencionadas, incluiré aquellas en las que el motivo ocupa al menos una estrofa, como el soneto de Damón (V, 481) y las coplas reales de Lenio (V, 536) en La Galatea y el soneto de Lotario (I, 34, 532) en el Quijote. Las otras ocho composiciones en las que aparece el tópico están todas en La Galatea: las coplas castellanas de Artidoro (II, 246, vv. 39-40), la égloga de los cuatro discretos y lastimados pastores (III, 348, v. 79; 353, v. 224; 350, vv. 128-133), la epístola de Timbrio a Nísida (III, 316, vv. 175-177), el vituperio de amor de Lenio (IV, 431, v. 18), la Canción de Tirsi en respuesta a Lenio (IV, 450, vv. 49-51; 451, v. 77), la Elegía de Meliso (VI, 551, vv. 48 y 96), las coplas reales de Damón (VI, 599, vv. 31-32) y los tercetos de Lauso (IV, 399, vv. 10-12; 400, v. 36). Fuera de la narrativa habría tres casos más: el soneto dedicado a Alonso Barros por su Filosofía cortesana moralizada, las redondillas «Al hábito de fray Pedro Padilla» (vv. 25-40) y la epístola a Mateo Vásquez (vv. 21-24), aunque en ninguno de los tres se trata de una navegación estrictamente amorosa, sino del mar de las pretensiones, de la vida o de la privanza respectivamente. Además, cabría mencionar madrigal de Pietro Bembo que don Quijote recita como propio (II, 68), que no incluyo en este conteo. 
activa del motivo, cambian las metáforas cristalizadas por la tradición e introducen nuevas relaciones para poder dar cuenta de sus situaciones particulares, ampliando las posibilidades expresivas de la tradición de la que parten.

\section{LOS SONETOS DE ERASTRO Y ELICIO: ENTRE LA TORMENTA PETRARQUISTA Y LA REVUELTA DE PASTORES}

Elicio y Erastro, los dos enamorados de Galatea, tienen una compleja evolución en la novela, que desemboca, como señala Avalle-Arce (1975), en una inversión de sus caracterizaciones iniciales. Ante la noticia del matrimonio de Galatea con un rico pastor extranjero, Erastro se lamenta platónicamente de que las riberas del Tajo sean privadas de su belleza, mientras que Elicio decide organizar una revuelta de pastores para disuadir y, de ser necesario, usar la fuerza contra el venerable Aurelio o contra el pastor lusitano. En este contexto, los personajes cantan sus sonetos de navegación amorosa, apropiando el tópico para expresar sus diferentes posturas ante la situación.

El primero en reaccionar poéticamente ante la noticia del matrimonio concertado es Erastro, quien, entre suspiros y «muestras de tierno dolor» ( $L a$ Galatea, V, 516), canta:

Por ásperos caminos voy siguiendo el fin dudoso de mi fantasía, siempre en cerrada noche, escura y fría las fuerzas de la vida consumiendo.

Y aunque morir me veo, no pretendo salir un paso de la estrecha vía: que, en fe de la alta fe sin igual mía, mayores miedos contrastar entiendo.

Mi fe es la luz que me señala el puerto seguro a mi tormenta, y sola es ella quien promete buen fin a mi viaje,

por más que el medio se me muestre incierto, por más que el claro rayo de mi estrella me encubra amor, y el Cielo más me ultraje (V, 517).

El primer verso, como han señalado Blecua $(1970,159)$ y Sánchez (1985, 32), retoma el «por ásperos caminos he llegado» del soneto VI de Garcilaso, cuyo tono fatalista está presente también en el soneto de Erastro ${ }^{5}$. El amor

5. Si bien los dos sonetos presentan una situación de dolor, Trabado Cabado resalta acertadamente la distancia que hay entre ambos, destacando la importancia que cobra la voluntad y la fe de Erastro en contraste con el soneto de Garcilaso (2000, 375-378). 
ideal del personaje no aspira a nada más que contemplar a Galatea y no resultarle enfadoso: «de vos espero / solo que consintáis que Erastro os quiera» (II, 265), dice el pastor en otro de sus sonetos. Sin embargo, incluso esta humilde posibilidad parece negársele con la promesa del matrimonio con el pastor extranjero que se llevaría a Galatea.

Ante esta situación, Erastro resalta que, aunque se siente morir por el dolor que implica no ver más a Galatea, no por ello dejará de amarla. Este giro resulta particularmente interesante en los tercetos, donde el personaje apropia el tópico de la navegación amorosa en una construcción que termina sobrepasando el idealismo del petrarquismo del que parte.

Erastro recurre a la identificación de la amada con una estrella, vinculándose a una tradición que establece la comparación de los ojos de la amada con estrellas-guía como submotivo del tópico de la navegación amorosa ${ }^{6}$. En un contexto metafórico igual al que presenta el personaje cervantino - de navegación en noche oscura y con tempestad-, la canzone LXXIII de Petrarca establece el símil: «Come a forza di vènti /stanco nocchier di notte alza la testa / a' duo lumi ch'à sempre il nostro polo, / così ne la tempesta / ch'i' sostengo d'Amor, gli occhi lucenti / sono il mio segno e 'l mio conforto solo» (vv. 46-51). Aceptando este sistema de correspondencias, si los ojos de la amada son la luz que guía, su 'encubrirse' implica la negación del puerto, el desastrado fin del amante, como se lee en el soneto CLXXXIX: "Celansi i duo miei dolci usati segni; / morta fra l'onde è la ragion et l'arte, / tal ch'incomincio a desperar del porto».

La amada-estrella del último terceto de Erastro se encubre: es Galatea a quien imagina lejos del Tajo, ajena a su vista. No obstante, el desarrollo que le da el personaje a este encubrirse no es el del Canzoniere, pues en el terceto anterior ha establecido que no es la amada-estrella lo que sigue ${ }^{7}$, sino la luz de su fe, que presenta como su única guía, en contraste con «il mio segno e '1 mio conforto solo» que es la amada-luz en la canzone de Petrarca.

De este modo, estamos ante una novedosa apropiación del tópico que plantea dos focos de luz: además de la tradicional estrella-amada, el amor

6. El tópico de los ojos de la amada como fuentes de luz es muy recurrente en la poesía de Erastro. De hecho, Blecua $(1970,175)$ y Sánchez $(1985,28)$ detectan un corte herreriano en el primer soneto del personaje basándose justamente en la importancia de este aspecto, que seguirá desarrollando en el resto de sus composiciones. Si bien me remito directamente al Canzoniere para resaltar el giro del soneto de Erastro frente al petrarquismo, es de notar la cercanía del uso de este sistema metafórico con la Canción III del Libro I de los versos de Herrera: «Va el piélago surcando presurosa / la nave, enderezada de la estrella / que gobierna su curso, y sin recelo / sufre la ira del ponto procelosa, / que con terror descarga toda en ella; / yo, en quien su saña toda vierte el cielo, / el hondo mar del celo / abro con frágil pino, y la Luz clara / veo anublarse y esconderse avara, / ondas gemir, subir el golfo en alto, / y cuán poco repara / mi vida de la muerte el duro asalto» (vv. 37-48).

7. Resulta interesante contrastar este soneto con las coplas castellanas que canta el personaje en el libro II, donde, desarrollando el tema de los ojos-luz, plantea su dependencia a ellos, al hecho de seguirlos: «Vea yo los ojos bellos / de este sol que estoy mirando, / y, si se van apartando, / váyase el alma tras ellos. / Sin ellos no hay claridad, / ni mi alma no la espere, / que, ausente de ellos no quiere / luz, salud ni libertad» (II, 305). La evolución del amor del personaje tiene un correlato en su poesía, rastreable desde esta metáfora de la amada como luz. 
mismo pasa a metaforizarse como luz en este soneto, una luz que, a diferencia de la estrella-amada, no está sujeta a vicisitudes externas, a la tópica posibilidad de encubrirse, y por ello promete -y diríase que asegura- el puerto. El 'puerto' como submotivo de la navegación amorosa, como explica Pilar Manero Sorolla, se configura como imagen de paz y sosiego frente a la 'tormenta' de las contrariedades en la historia de amor $(1990,225)$, y es este el sentido que tiene en el soneto de Erastro. No obstante, no estamos en este caso ante la tópica metáfora de la feliz unión de los amantes. A partir del amor-luz-guía del personaje, que no depende de la luz de su estrella, el puerto se resignifica y pasa a aludir a una promesa de felicidad en el mismo hecho de amar, posibilidad a la que apunta el personaje a lo largo de la novela con su insistente no esperar nada.

Un proceso poético opuesto al de Erastro es el de Elicio. Este personaje canta su soneto de navegación amorosa al final de la novela en medio de un arquetípico amanecer poético de «fresca aurora, con sus hermosas y variadas mejillas $[\ldots]$ aljofarando las hierbas y pintando los prados», en el que tampoco faltan las tópicas «parleras aves con mil suertes de consabidas cantilenas» (VI, 627-628), que, sin embargo, va a preceder a la aparición de las escuadras de pastores que ejecutarán su plan. En sintonía con tan entreverado marco narrativo, el soneto recurre a un sistema metafórico petrarquista para expresar una realidad tan antipoética como la mencionada revuelta de pastores y sus posibles consecuencias:

\footnotetext{
Si de este herviente mar y golfo insano, donde tanto amenaza la tormenta, libro la vida de tan dura afrenta y toco el suelo venturoso y sano,

al aire alzadas una y otra mano, con alma humilde y voluntad contenta, haré que Amor conozca, el Cielo sienta que el bien les agradezco soberano.
}

Llamaré venturosos mis sospiros, mis lágrimas tendré por agradables, por refrigerio el fuego en que me quemo.

Diré que son de amor los recios tiros, dulces al alma, al cuerpo saludables, y que en su bien no hay medio, sino extremo (VI, 627).

Elicio también recoge el motivo de la tormenta amenazante que empieza a formarse sobre el ya desapacible mar de sus amores. No obstante, estos elementos inquietantes solo se nombran para enunciar la posibilidad de superarlos, dependen de una estructura condicional cuyo segundo término, las 
felices consecuencias que derivarían de esta posibilidad, se desarrollan en el resto del soneto ${ }^{8}$.

Si bien este optimismo parece ajeno al motivo mismo, ya la lírica de Boscán había dado este giro hacia la esperanza frente al Canzoniere en la elaboración del tópico 9 . Elicio, como poeta, sigue la estela del bardo catalán, sin embargo, a la luz de su contexto narrativo, hay una transformación del sentido de los submotivos. En la historia del personaje, la peligrosa situación de la que espera salir victorioso es la revuelta de pastores. De este modo, el motivo de la tormenta se vacía de su contenido tradicional, de las tópicas dificultades amorosas, y pasa a contener una realidad tan prosaica como la lucha de pastores que parece estar por estallar.

Asimismo, el optimismo boscaniano del soneto, el «tocar el suelo venturoso y sano» superando la tempestad, se resignifica en el contexto ficcional del personaje, donde se sugiere que, en caso de que Elicio triunfe y logre liberar a Galatea del matrimonio con el pastor extranjero, la desamorada pastora le quedaría «obligada» y terminaría casándose con él ${ }^{10}$. El motivo del puerto o arribo a tierra pasa a contener entonces un término de realidad completamente insólito desde las coordenadas de la tradición de la que parte: un matrimonio sin amor, una unión forzada por una coerción social, como lo es ese «quedar obligada».

Ante esta posibilidad de ver a Galatea no solo fuera del «poder ajeno» ${ }^{11}$, sino, además, suya, Elicio declara en el segundo cuarteto que quedaría con la «voluntad contenta». Los tópicos suspiros, lágrimas, fuego o incluso las armas de amor -motivos todos recurrentes del petrarquismo-, que en la historia de Elicio remiten al lacerante amor no correspondido, se desactivan en los tercetos y con ellos todo el idealismo del soneto y del personaje.

La evolución de los dos personajes -y la propuesta de Cervantes en $\mathrm{La}$ Galatea - tiene un perfecto correlato en la poesía ${ }^{12}$. La poesía de Erastro tiende, como el personaje, a una idealización cada vez mayor. Aquel 'simple' pastor, que en el primer canto alterno con Elicio daba cabida en sus versos a

8. Trabado Cabado estudia esta estructura y relaciona el tema del feliz agradecimiento que desarrolla Elicio con el submotivo de la ofrenda votiva (2000, 380-382).

9. Para el giro optimista que le da Boscán al tópico frente a la tradición petrarquista y del amor cortés, ver Sarmati (2009, 125-126). Recuérdese, a este propósito el soneto C: «En alta mar rompido está el navío / con tempestad y temeroso viento, / pero la luz que ya amanecer siento, / y aun el cielo me hacen que confío. / La estrella, con la cual mi noche guío, / a vueltas de mi triste laxamiento, / alzo los ojos por mirarla atento, / y dice que, si alargo, el puerto es mío».

10. Dice Erastro: «Tenía por bien empleado que Elicio la alcanzase, como lo imaginaba, pues tanto Galatea le había de quedar obligada» (VI, 629, la cursiva es mía).

11. Recuérdese que, ante la noticia del matrimonio concertado con el pastor lusitano, Elicio, a diferencia de Erastro, termina declarando un amor más mundano y reconociendo que se complacía en «ver que, si no me quería [Galatea], no me aborrecía, y que ningún otro pastor se podía alabar de que aun de ella fuese mirado» (V, 506, la cursiva es mía), y no tolera la idea «de ver a Galatea en poder ajeno» (V, 507).

12. Para la evolución poética de Elicio, Erastro y Galatea y su relación con el desarrollo de la novela ver Santa-Aguilar (2018a). 
su ganado y a sus perros ${ }^{13}$, es quien termina desanclando el sistema metafórico petrarquista de cualquier vicisitud externa al hecho mismo de amar. Por el contrario, el ideal Elicio, que abría poéticamente la novela con la arquetípica queja a Eco y con el tópico acrecentar los ríos con su llanto ${ }^{14}$, termina 'invitando' a los elementos menos poéticos, como la revuelta de pastores, no solo a la trama de la novela, sino también a sus endecasílabos. Ambos personajes transforman el motivo de la navegación amorosa. Sin embargo, cabría subrayar que es Erastro quien lleva a cabo una transformación 'activa' que va más allá del proceso de recontextualizar los tópicos a la luz de su historia. El 'rústico' que por su supuesta falta de entendimiento no es tenido por rival de Elicio, es quien, en esta particular propuesta pastoril que continuamente viola las expectativas del lector, lleva a cabo una transformación que trasciende el contexto narrativo, una transformación estructural del sistema metafórico que habría que registrar en las historias de este motivo literario.

\section{DE NAVEGANTES Y VOTOS: LOS SONETOS DEL REENCUENTRO DE TIMBRIO Y SILERIO}

También en el marco narrativo de La Galatea, Damón, Timbrio y Silerio reelaboran el tópico de la navegación amorosa. El contexto de estos tres sonetos de navegación es el del rencuentro de los dos inseparables amigos, los cortesanos Timbrio y Silerio. Damón lo introduce con un soneto en el que el tópico de la navegación, desarrollado en los cuartetos, anticipa lo que está a punto de suceder:

Si el áspero furor del mar airado por largo tiempo en su rigor durase, mal se podría hallar quien entregase su flaca nave al piélago alterado.

No permanece siempre en un estado el bien ni el mal, que el uno y otro vase; porque si huyese el bien y el mal quedase, ya sería el mundo a confusión tornado.

La noche al día, y el calor al frío, la flor al fruto van en seguimiento, formando de contrarios igual tela.

13. «Yo te prometo, Elicio, que le diera / todo cuanto en la vida me ha quedado / a Galatea, porque me volviera / el alma y corazón que me ha robado; / y después del ganado le añadiera / mi perro Gavilán con el Manchado; / pero, como ella debe de ser diosa, / el alma querrá más que no otra cosa (I, 179, vv. 57-64).

14. Aunque las octavas reales con las que el personaje abre la novela contienen todos los topoi de la poesía bucólica, hay ya una primera sutil fractura, pues ni la naturaleza ni el eco muestran la arquetípica empatía con el dolor del personaje. Para este tema ver Santa-Aguilar (2018a). 
La sujeción se cambia en señorío en placer el pesar, la gloria en viento, chè per tal variar natura è bella $(\mathrm{V}, 481)$.

Silerio ha llegado a las riberas del Tajo desesperado, pensando que Nísida, la amada de su amigo, de quien él también está enamorado, ha muerto por su culpa, por haber olvidado una señal que habían acordado le daría en caso de que Timbrio saliese con vida de un duelo. Sin embargo, tanto la dama, que solo había sido presa de un terrible desmayo, como su amigo llegan a las riberas del Tajo, donde Silerio pretendía acabar la vida de dolor. La historia de los cortesanos pasará de la desdicha a la dicha a partir de este reconocimiento, tal como lo anuncia el soneto de Damón, que se articula como la más apropiada obertura para la escena que introduce.

El soneto de Damón evoca el tópico horaciano de la execración de la navegación ${ }^{15}$. No obstante, este personaje le da un giro completamente original y lo usa con el sentido contrario. Si bien el contraste entre «la flaca nave» y el «piélago alterado» o «el furor del mar airado» parecen conducir a la tradicional condena del incauto navegante, lo que hace este soneto es justificar a ese navegante, pasando de la execración prácticamente a una invitación. Damón subordina el motivo a una estructura condicional que el soneto se encargará de negar: el «áspero furor del mar airado» no es durable, condición que anula la condena (el «mal se podría hallar quien entregase / su flaca nave al piélago alterado»). El tema de la mutabilidad del que depende este uso del tópico de la navegación tampoco se emplea en este soneto con su tradicional sentido moral de advertencia, sino todo lo contrario: para predicar la no permanencia de la desdicha, el paso del infortunio a la dicha, «de la sujeción al señorío», que es lo que está a punto de suceder en la historia de los cortesanos. Resulta interesante también destacar que, en el último verso, cita del soneto XLVIII de Serafino Aquilano, la conclusión de toda esta reflexión sobre la mutabilidad no es moral sino estética ${ }^{16}$ : remite a la belleza de la tela del primer terceto que tejen los contrarios en la naturaleza. Damón es un personaje cuya presencia en La Galatea obedece únicamente a motivos estéticos: no tiene ninguna historia, ningún desarrollo narrativo; aparece porque ha sido invitado, junto con Tirsi, a la boda de Daranio y Silveria por su fama como poeta. De este modo, resulta coherente no solo que despliegue su destreza para darle un revés al tópico, sino también que esa innovación poética lo arrastre precisamente al plano de la estética, el plano que justifica su presencia en la obra.

15. Se trata de un motivo desarrollado en la $O d a$ I, 3, que, como destaca Antonio Ramajo Caño (2001), tuvo gran difusión en el Siglo de Oro, con ecos que van desde el Broncese hasta Quevedo o Góngora y, con ella, el uso de motivo de la execración de la navegación para aludir a la insensatez humana que se fía de la fortuna variable. Petrarca en la sextina LXXX elabora este tópico horaciano referido a la navegación de amor.

16. Agradezco esta observación al profesor Ignacio Arellano. 
Después del canto de Damón, Timbrio interviene poéticamente con un soneto «que en el tiempo del hervor de sus amores había hecho, el cual de Silerio era sabido como del mesmo Timbrio» (V, 481), con el cual busca ser reconocido por su amigo:

Tan bien fundada tengo la esperanza, que, aunque sople riguroso viento, no podrá desdecir de su cimiento: tal fe, tal fuerza y tal valor alcanza.

Tan lejos voy de consentir mudanza en mi firme, amoroso pensamiento, cuan cerca de acabar en mi tormento antes la vida que la confianza.

Que si al contraste del amor vacila el pecho enamorado, no merece del mesmo amor la dulce paz tranquila.

Por esto el mío que su fe engrandece, rabie Caribdis o amenace Cila, al mar se arroja y al amor se ofrece $(\mathrm{V}, 520)$.

$\mathrm{Su}$ soneto, como se lee en el primer verso, es un soneto de esperanza. Timbrio recurre a los peligros marinos, submotivos tópicos para referir las contrariedades en la historia amorosa, para oponerlos a la firmeza del enamorado, que garantizaría un buen fin. Aunque el puerto no se nombra, siguiendo la metáfora de la navegación, quedaría aludido en el último verso del primer terceto, «del mesmo amor la dulce paz tranquila», la tradicional unión final de los amantes. Es de notar que en este soneto no hay estrellas-guía. La apropiación del tópico se centra exclusivamente en la firmeza del amante, a partir de la cual el personaje propone una 'justicia poética' que excluiría de este final feliz al amante mudable y premiaría al firme. Con base en esta lógica, el personaje desarrolla el tema de su confianza, que lo lleva a desafiar a las míticas Caribdis y Escila, los peligros por excelencia de la navegación, asegurándose un triunfo.

Este soneto tiene además un interés añadido a la luz del contexto narrativo, el cual posibilita una lectura tanto metafórica como literal. En efecto, Timbrio no es solo el enamorado que figura su sentir a través del tópico de la navegación amorosa, también, en las peripecias de esta historia cortesana, termina siendo un navegante: «al mar se arroja» preso del dolor por la presunta muerte de su amada Nísida y allí queda a punto de perder la vida en medio de una borrasca de «riguroso viento» que llega a romper el árbol y las velas de su navío (V, 484). No obstante, como dijera Damón en su soneto, la tormenta cesa y el navegante salva la vida, y pasa además del infortunio a la dicha, pues se reencuentra en la nave con su amada, que había salido en busca de los engañados caballeros. Así, la historia del personaje confirmará el 
contenido su soneto, pues este amante firme al final de sus peripecias marinas terminará gozando «del mesmo amor la dulce paz tranquila».

También en este contexto del feliz reencuentro, Silerio apropia el tópico de la navegación amorosa para referir su historia, que es la de un doloroso amor por la amada de su amigo y un final arreglo matrimonial con la hermana de esta. En este punto es pertinente recordar que Silerio, enamorado de Nísida, es descubierto por su amigo Timbrio lamentándose poéticamente de la encrucijada en la que se encuentra. Ante tal imprevisto, Silerio niega su amor y convence a su amigo de que no está enamorado de Nísida, sino de Blanca, la hermana.

Después del reencuentro de los amigos, Timbrio le comunica a Silerio que Blanca se ha enamorado de él, y a partir de ese momento se da un constante rogar e insistir $^{17}$ a Silerio que se case con ella, cosa que no hace más que enfatizar que el personaje no la ama. Sin embargo, Silerio termina accediendo a casarse y es en este momento que canta su soneto:

Gracias al Cielo doy, pues he escapado

de los peligros de este mar incierto,

$\mathrm{y}$ al recogido, favorable puerto,

tan sin saber por dónde, he ya llegado.

Recójanse las velas del cuidado;

repárese el navío pobre, abierto;

cumpla los votos quien con rostro muerto

hizo promesa en el mar airado.

Beso la tierra, reverencio al Cielo, mi suerte abrazo mejorada y buena, llamo dichoso a mi fatal destino,

y a la nueva, sin par, blanda cadena, con nuevo intento y amoroso celo, el lastimado cuello alegre inclino (V, 521).

El primer verso, como lo nota Sánchez (1985, 34), remite al soneto XXXIV de Garcilaso. A la luz de la historia del personaje, el intertexto es

17. «Y con esto aconsejó Timbrio a su amigo fuese contento de que Blanca le tuviese, escogiéndola y aceptándola por esposa [...] encareciéndole el gusto y placer que los dos tendrían viéndose con tales hermanas casados. Silerio le respondió que le diese espacio para pensar en aquel hecho, aunque él sabía que al cabo era imposible dejar de hacer lo que él le mandase» (V, 499-500, la cursiva es mía). Timbrio también dice a los pastores que «había de procurar con toda su industria y fuerzas que Silerio viniese en lo que Blanca deseaba, suplicándoles que todos fuesen en ayudar $y$ favorecer su intención [...] quería que todos a Silerio rogasen diese el sí de recibir a Blanca por su legítima esposa» (V, 503, la cursiva es mía). Timbrio y los pastores que lo acompañan «determinaron volver a la ermita a rogar a Silerio aceptase a la hermosa Blanca por su esposa» (V, 505, la cursiva es mía), y, finalmente, cuando se refiere que los dos personajes se han casado, se aclara que Timbrio y Nísida «se lo persuadieron» $(\mathrm{V}, 519)$. 
revelador, pues el bardo toledano refiere el tópico de la navegación amorosa al desamor, a la posibilidad de escapar del mar y poder contemplarlo desde la tierra firme: «Gracias al cielo doy que ya del cuello / del todo el grave yugo he desasido, / y que del viento el mar embravecido / veré desde lo alto sin temello». Siguiendo de cerca a Garcilaso, Silerio se presenta como el náufrago que ha salvado la vida de las tormentas amorosas. Además, en el soneto de Silerio este sentido se contamina con otro submotivo de la navegación amorosa propio del desengaño de amor, como lo es el tema horaciano de la ofrenda votiva, de amplia difusión en el Siglo de Oro ${ }^{18}$.

Si bien en el soneto de Silerio no hay una ofrenda como tal, resulta interesante la mención en el segundo cuarteto a unos votos hechos en medio del peligro del «mar airado», que ahora debe cumplir. A la luz de la historia del personaje, tales votos remiten a la palabra que ha dado a Timbrio asegurándole que está enamorado de Blanca ante el peligro que implicaba haber sido descubierto por su amigo cantando su amor por Nísida. Después de las peripecias de este amor imposible, que lo llevan al extremo del dolor y la desesperanza creyendo a la amada muerta y al amigo perdido (el naufragio de los cuartetos que lo deja con la «nave abierta»), Silerio se encuentra ante la no pensada ventura de verse reunido con ambos y en este contexto 'cumple los votos'; actúa conforme a lo que había asegurado a su amigo y termina casándose con Blanca.

El «fatal destino» del personaje, su doloroso amor por la amada de su amigo, a la luz de esta no pensada ventura, puede llamarse «dichoso». Sin embargo, es una dicha parcial, que claramente no remite al puerto como feliz unión de los amantes, pero tampoco termina de encajar con el jubiloso desengaño de amor del soneto de Garcilaso, que se impondrá en poetas posteriores como Góngora o Quevedo ${ }^{19}$. En un punto medio, que tampoco es la recaída de amor (como la del soneto VII de Garcilaso o del CLXII de Lope), y con unos términos que vuelven a hacer eco del soneto XXXIV de Garcilaso, Silerio tematiza en los tercetos los particulares de su situación: volver a ofrecerse al amor, pero a un amor que realmente no es tal, a una cadena que resulta «blanda», a la que solo puede ofrecer un cuello que otra sí ha logrado lastimar.

\section{Puertos negados: De La GaLATEA AL PERSILES}

De La Galatea al Persiles, Cervantes presenta varias historias que acaban en la desdicha. Algunos personajes, como Lotario y más directamente Ansel-

18. Se trata de la Oda a Pirra (I, 5) de Horacio, donde el poeta tematiza la ofrenda hecha al dios del mar-sus húmedas ropas- en agradecimiento por haber librado la vida de la infructuosa navegación de su amor por Pirra y como escarmiento para futuros navegantes. Para la influencia de este tema en la poesía de los Siglos de Oro ver Bistué Guardiola (1996), Ramajo Caño (2001) y Davis (2004).

19. Ver, por ejemplo, el soneto de Quevedo «Qué bien me parecéis jarcias y entenas» o el romancillo de Góngora «Noble desengaño». 
mo en El curioso impertinente, labran paso a paso los caminos de su infelicidad, pero otros, como Lenio en La Galatea o el enamorado portugués en el Persiles, llegan simplemente a ella sin culpa alguna, en contravía de la noción de justicia poética que se esboza en sus contextos narrativos.

El caso de Lenio en La Galatea es paradigmático en este sentido. El personaje, enemigo del amor, termina enamorado de otra pastora también desamorada. Hasta este punto, como señalan los demás pastores que han tenido que soportar continuamente sus implacables denuestos al amor, se podría creer que al desamorado Lenio se le hace 'justicia' ${ }^{20}$. Sin embargo, de su caracterización y de la de quien se enamora, que es su viva copia femenina, se esperaría que, después de la humillación de verse sometido a los efectos de amor, se le permita gozar de un amor correspondido ${ }^{21}$. No obstante, la pastora Gelasia no perderá su condición de desamorada, y Lenio quedará sumido en su desdicha indefinidamente.

El arrepentido pastor apropia el tópico de la navegación amorosa en unas coplas reales con las que se disculpa ante Amor:
Estas cosas bien sabidas, han agora descubierto en mis entrañas rendidas que tú solo eres el puerto do descansan nuestras vidas. Tú, la implacable tormenta que al alma más atormenta, vuelves en serena calma; tú eres gusto y luz del alma, y manjar que la sustenta $(\mathrm{V}, 536)$.

Lenio no es uno de los mejores poetas de La Galatea, pero, como estrategia de su captatio benevolentiae ante Amor, termina modificando también los submotivos de la navegación amorosa. El personaje cervantino parece tomar como referente el capítolo XXIV de las Rime de Ariosto: "Voi m'acquietate, e ritenete in pace / [...] / Voi sète il porto del mio navicare, / voi calamita sète e la mía stella, /qual sola seguo e che sempre m'appare. / Voi sola nel furor d'ogni procella / chiamo al mio scampo, e risona 'l bel nome» (vv. 7-14). La estructura reiterada de dirigirse a una segunda persona al inicio del verso, así como el sistema metafórico que equipara a la amada

20. Dice Erastro en respuesta a los vituperios de amor de Lenio: «Paréceme, Lenio, que tus desvariadas razones merecen otro castigo que palabras; mas yo espero que algún día pagarás lo que agora has dicho, sin que te valga lo que en tu defensa dijeres» (I, 234-235), y Arsindo, cuando ya lo ven enamorado: «El amor ha querido vengarse del rebelde corazón de Lenio» (V, 530). También el mismo Lenio, arrepentido, afirma ante Tirsi, pastor con el que lleva a cabo una disputa poético-conceptual defendiendo el desamor: "Ahora puedes, famoso pastor, tomar justa venganza del atrevimiento que tuve de competir contigo, defendiendo la injusta causa que mi ignorancia me proponía» $(\mathrm{V}, 537)$.

21. Nótese que esta es justamente la estructura que sigue la historia de Teolinda, con la que no en vano se entreteje la de Lenio. Para el estudio de esta estructura ver Santa-Aguilar (2018b). 
con el puerto, la estrella y lo que salva de la tormenta, aparece en la copla de Lenio, aunque referido al Amor, con quien pretende congraciarse.

Este giro teje una significativa relación intertextual con la disputa poéticoconceptual que llevan a cabo Tirsi y el mismo Lenio sobre el amor en el libro IV. Tirsi, como defensor de amor, ya lo definía como «farol que no se encubre, / mas nos descubre el puerto en la tormenta» (IV, 450). Lenio está retomando entonces la oposición entre amor y tormenta de Tirsi en estas coplas, dándole la razón con este guiño a su antiguo contrincante, a la vez que desmiente su vituperio, en el que caracterizaba al amor como «turbado mar do no se ha visto calma» (IV, 431). La evolución narrativa del personaje, su paso del desamor al amor, traza también un recorrido poético paralelo que culmina en la presentación del amor como puerto, pues ahora, después de las disculpas y el arrepentimiento, el personaje funda en el amor todas sus esperanzas de llegar a la felicidad.

Sin embargo, a la luz del contexto narrativo, este nuevo sistema metafórico que plantea Lenio, así como las promesas que introduce la estructura de su historia, serán negados, pues su amor por la pastora Gelasia no será correspondido. Su amor nunca será puerto y lo dejará sumido en tópica tormenta del dolor y las dificultades.

Dejando La Galatea, donde está la mayor parte de este corpus de navegación amorosa $-\mathrm{y}$ del corpus petrarquista ${ }^{22}$, el tópico volverá a aparecer en la historia de El curioso impertinente, en uno de los sonetos que recita Lotario ante Camila cuando ya es su amante pero finge ante su amigo Anselmo que sus intentos de seducción han fracasado:

Yo sé que muero, y si no soy creído, es más cierto el morir, como es más cierto verme a tus pies, ¡oh bella ingrata!, muerto, antes que de adorarte arrepentido.

Podré yo verme en la región de olvido, de vida y gloria y de favor desierto y allí verse podrá en mi pecho abierto cómo tu hermoso rostro está esculpido.

Que esta reliquia guardo para el duro trance que amenaza mi porfía, que en tu mismo rigor se fortalece.

¡Ay de aquel que navega, el cielo escuro, por mar no usado y peligrosa vía adonde norte o puerto no se ofrece! (I, 34, 352).

22. Manero Sorolla resalta esta preeminencia del petrarquismo en la poesía inserta en La Galatea, particularmente en los endecasílabos (1991, 761). 
El soneto reproduce hasta cierto punto el fingimiento que llevan a cabo Camila y Lotario ante Anselmo, pues recurre al tópico del rigor de la amada y a su caracterización como 'ingrata', aunque declara un amor que realmente siente su autor ficcional. Dentro de la mentira que los dos amantes quieren representar ante Anselmo, se anuncian unas fatales consecuencias, que, desde el contexto de enunciación, apuntan al supuesto dolor de no ser correspondido. No obstante, estas 'mentiras', estas fatales consecuencias, como advierten lúcidamente Zimic $(2003,79)$ y Mata Induráin $(2005,153)$, pasarán a ser 'verdad', con lo cual el soneto se carga de un carácter anticipatorio en la intrincada estructura de esta novela inserta donde todos los fingimientos terminan haciéndose realidad y todas las advertencias fracasan estrepitosamente ${ }^{23}$.

En este contexto de insospechadas anticipaciones, el sentido del soneto, el contenido de sus metáforas, se duplica: por un lado, está el que le da intencionalmente Lotario en el contexto de enunciación y, por otro lado, está el que adquiere a la luz del desenlace de la historia.

El tópico de la navegación amorosa, como cierre estructural, condensa los presagios negativos del soneto, además, bajo la forma de una (inútil) advertencia. Siguiendo la línea de la execración de la navegación, Lotario condena al navegante que se ofrece a un mar peligroso, que en este caso es un amor ilícito por la mujer de su mejor amigo. A la luz de este contexto metafórico, surge el submotivo del puerto, que bifurcará su sentido en esta estructura de mentiras y anticipaciones. En el contexto de enunciación, el puerto tiene el tradicional sentido de la unión de los amantes, que Lotario y Camila quieren mostrar como algo que se niega, dando a entender a Anselmo que los intentos de seducción de Lotario han fracasado.

Sin embargo, a la luz del final de la novela, esta imagen cobra otro sentido. El amor de Lotario sí es correspondido, pero es justamente esto lo que desencadena el trágico desenlace, pues Anselmo descubre la traición, muere de pesar y Lotario decide ir a la guerra donde acaba pronto «de vida y gloria y de favor desierto». A la luz de las veras de esta infructuosa historia de amor, la unión de los amantes no puede ser metafóricamente un 'puerto', pues se opone desde el principio a la paz y el sosiego que funcionan invariablemente como término de relación del submotivo en todos sus posibles desarrollos. No obstante, la advertencia del terceto cobra particular validez en este desenlace, pues la conclusión de haber seguido una navegación en el «mar no usado y peligrosa vía» de ese amor trasgresor va a ser justamente la negación de un 'puerto', entendido ahora en el amplio sentido de esa paz y sosiego que subyace a la construcción misma de la metáfora y que había quedado excluido de la unión de estos amantes.

También en el Persiles Cervantes volverá sobre el motivo en el soneto del enamorado portugués. Manuel de Sosa Coitiño, abandonado por su amada Leonora, que ha decidido entrar a un convento, canta un soneto de navegación amorosa antes de morir de pena:

23. Para esta estructura ver Santa-Aguilar (2015). 
Mar sesgo, viento largo, estrella clara, camino aunque no usado alegre y cierto, al hermoso, al seguro, al capaz puerto llevan la nave vuestra única y rara.

En Scilas ni en Caribdis no repara ni en peligro que el mar tenga encubierto, siguiendo su derrota al descubierto, que limpia honestidad su curso para.

Con todo, si os faltara la esperanza de llegar a este puerto, no por eso giréis las velas, que será simpleza.

Que es enemigo amor de la mudanza y nunca tuvo próspero suceso el que no se quilata en la firmeza (I, 9, 196).

Este soneto es uno de los pocos poemas insertos que ha contado con bastante atención por parte de la crítica ${ }^{24}$. Como ha sido destacado en diversas ocasiones, ofrece la particularidad de presentar una disociación entre la voz poética y el amor que canta, ya que el abandonado Manuel no canta su amor, sino el de Leonora por Cristo ${ }^{25}$.

Del desarrollo del tópico de la navegación amorosa y de sus rupturas con el petrarquismo se ha encargado en detalle Isabel Lozano-Renieblas (2004) y poco hay que agregar después de su estudio. Como señala la autora, la identificación de la amada con la nave no es usual, aunque tiene como precedente la canzone CCCXXIII de Petrarca ${ }^{26}$, en la que se alude a la amada como una nave, entre otras alegorías, para presentar su muerte como un naufragio:

Indi per alto mar vidi una nave, con le sarte di seta, et d'òr la vela, tutta d'avorio et d'ebeno contesta; e 'l mar tranquillo, et l'aura era soave, e 'l ciel qual è se nulla nube il vela, ella carca di rica merce honesta: poi repente tempesta orïental turbò sí l'aere et l'onde, che la nave percosse ad uno scoglio. O che grave cordoglio! Breve hora oppresse, et poco spatio asconde, l'alte ricchezze a nul'altre seconde (vv. 13-24).

24. Para la buena acogida ver Lozano-Renieblas (2004, 300-301). Manero Sorolla lo incluye en su estudio del tópico $(1990,224)$.

25. Lozano-Renieblas $(2004,305)$, Alcalá-Galán $(2009,191)$ y Montero Reguera $(2011,254-255$; 2013, 129-131) se encargan de resaltar tal disociación.

26. Manero Sorolla recoge en su estudio otros dos casos de esta identificación (1990, 215 y 219): el primero, en De Jennaro (Rime, XVI, 11-14, vv. 1-4) y el segundo en Tasso (Rime, 1245, vv. 1-4). 
A partir de este referente, Lozano-Renieblas sugiere la posibilidad de que la nave «al descubierto» del soneto de Manuel tenga el propósito de establecer un contraste con la rica nave de la alegoría de Petrarca $(2004,304)$. Sin embargo, creo que a la luz de la historia de Manuel hay otra posible lectura del diálogo intertextual con la canzone. En efecto, es de notar que la presentación de la rica nave de Petrarca no dista mucho de la que hace Manuel de Leonora el día que iba a desposarse con él:

Vestida de raso blanco $[\ldots]$ con ricas y gruesas perlas. Venía forrada la saya en tela de oro verde [...] la cintura, collar y anillos que traía, opiniones hubo que valían un reino. Torno a decir que salió tan bella, tan costosa, tan gallarda y tan ricamente compuesta y adornada que causó invidia en las mujeres y admiración en los hombres (I, 10, 203).

Después de esta descripción, es significativo también que Leonora anuncia su decisión de entrar al convento y acto seguido la priora la desnuda de todas sus riquezas, como si fuera la nave petrarquesca que no muere, pero naufraga para el amor de Manuel.

A diferencia de la canzone de Petrarca, donde la imagen se usa únicamente como alegoría de la muerte, Manuel con su amada-nave se ceñirá al tópico de la navegación amorosa en su soneto, en este caso 'a lo divino', un tratamiento que también tiene un precedente en el cierre del Canzoniere, en la canzone CCCLXVI, que aprovecha la figuración de la Virgen como estrella dentro de la navegación espiritual ${ }^{27}$. En este contexto, Manuel propone a Leonora la firmeza como elemento garante de la felicidad en el amor ${ }^{28}$.

En este punto, los paralelos con el soneto de Timbrio resultan evidentes. Desde el modo de enfocar la navegación en el tema de la firmeza como único elemento garante del «próspero suceso» («Que si al contraste del amor vacila / el pecho enamorado, no merece / del mesmo amor la dulce paz tranquila»), hasta los submotivos de las temibles Escila y Caribdis, evocados para ser anulados en el contraste con la firmeza del amante. Sin embargo, las historias de los dos autores ficcionales $y$, por ende, las relaciones que se tejen entre contexto narrativo y poema, son opuestas. En el caso de Timbrio se da una exacta correspondencia entre su soneto y sus peripecias tanto a nivel literal como metafórico: el personaje termina efectivamente navegando y salvando la vida de las tormentas y peligros marinos para llegar a gozar finalmente de un feliz amor correspondido. En el caso de Manuel, por el contrario, esa promesa del soneto se ve condenada al fracaso, pues este personaje, que

27. «Vergine chiara et stabile in eterno, / di questo tempestoso mare stella, / d'ogni fedel nocchier fidata guida / pon'mente in che terribile procella / i' mi ritrovo sol, senza governo / et ò già da vicin l'ultime strida» (vv. 66-71). Para un estudio de las fuentes de esta metáfora ver Micozzi (1995, 718).

28. Lozano-Renieblas destaca este elemento del soneto como otra importante ruptura frente a la configuración del amante petrarquista, subrayando que el enamorado Manuel no construye su soneto como un pathos lírico sino como un ethos, dictando a Leonora el 'deber ser' en su navegación amorosa (2004, 302, 304-306). 
también termina navegando, muere de dolor en medio de las heladas aguas septentrionales, a pesar de haber encarnado todas las condiciones del amante firme que prescribe ${ }^{29}$.

\section{De Claribea a una Clara y luciente estrella: el romance DE DON LUIS Y LA NAO DE AMOR DEL FELIXMARTE DE HIRCANIA}

El romance de don Luis inserto en el Quijote también ha contado con más atención en la crítica $^{30}$. En la venta donde terminan alojándose los protagonistas de las historias intercaladas de la Primera parte, el narrador refiere que «llegó a los oídos de las damas una voz tan entonada y tan buena, que les obligó a que todas le prestasen atento oído» (I, 42, 446). La voz resulta ser del joven don Luis, que ha huido de casa de su padre vestido de mozo de mulas detrás de su amada doña Clara, que va de viaje con su padre el oidor. Lo que canta el joven es un romance de navegación amorosa, tal vez aquel en el que se desarrollan más detalladamente los tradicionales submotivos del tópico: el amante como marinero, el amor como el mar, la amada como estrella, las dificultades como nubes que la encubren y el puerto como la final unión de los amantes:

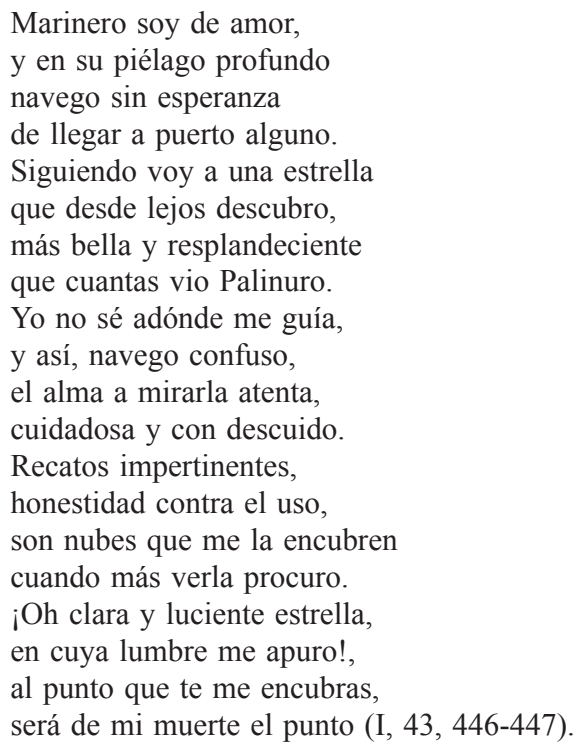

29. Zimic $(2005,38$ y 45) y Armstrong-Roche $(2011,27)$ resaltan esta no correspondencia entre las promesas del soneto y la historia de su autor. Lozano-Renieblas $(2004,306)$ y Mata Induráin (2004, 660) subrayan que Manuel se construye como el enamorado firme y honesto del soneto.

30. Véase, por ejemplo, Mata Induráin (2007) o Romo Feito $(2012,147)$ para unos cuidadosos análisis literarios. 
El uso de los submotivos es completamente tópico, sin embargo, a la luz de la historia de don Luis, amplían su sentido y terminan funcionando tanto metafórica como literalmente (Zimic 2003, 176; Mata Induráin 2007, 135-136), como ocurría en el soneto de Timbrio, pues se trata de un personaje que, si bien no es navegante, sí se desplaza siguiendo a su amada. Además, como lo notan Mata Induráin $(2007,135)$ y Romo Feito (2012, 147), la amada se llama justamente Clara, la «clara y luciente estrella» del verso 17.

En este punto, cabría señalar algunos paralelos con la inserción de la nao de amor del Felixmarte de Hircania ${ }^{31}$. En el capítulo XL del libro primero de la obra de Melchor de Ortega, el emperador de Grecia y su familia se van a pasar unos días de verano a un monasterio. Allí, las damas son sorprendidas por la admirable voz de un desconocido mancebo que canta una nao de amor:

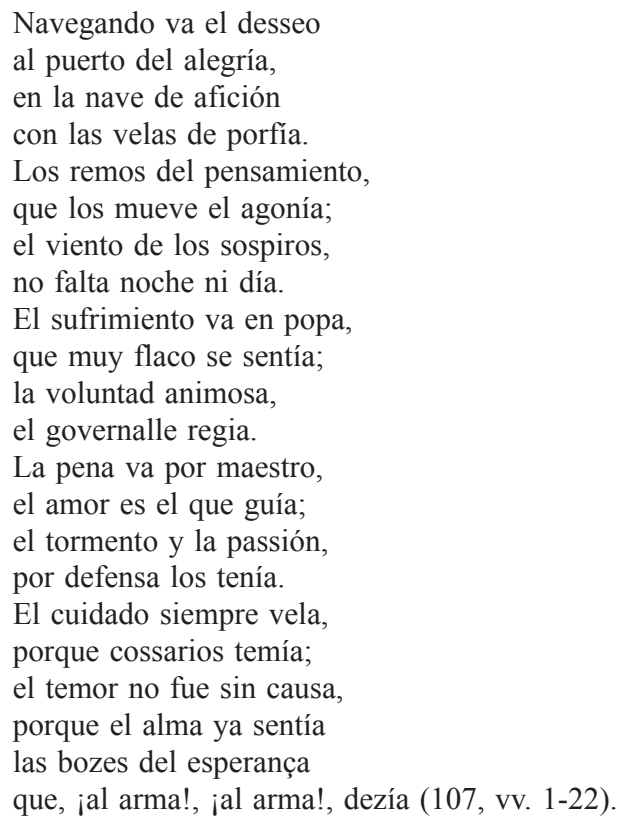

Sobre la cual comenta el narrador:

Tanta era la suavidad que no quisieran dejar de oírla. Mas la que esto sintió de veras fue aquella excelente y hermosa princesa Claribea con una nueva alteración que sin entender de qué le viniese al coraçón, adevinando lo que le avía de subceder, y reprehendiéndose, aunque niña, porque era la más honesta y acabada bondad que en el mundo avía (107).

31. Para un estudio de la nao de amor del Felixmarte y de la poesía inserta en las novelas de caballerías ver Aguilar Perdomo (2001). 
La nao del doncel no guarda mayor semejanza con el romance de don Luis, pues centrará el motivo de la navegación en la construcción metafórica de la nave. No obstante, hay dos elementos que cabría destacar. Por un lado, es de notar que dentro de este corpus cervantino el romance de don Luis es la composición que desarrolla más detalladamente las correspondencias metafóricas, un procedimiento propio de las naos ${ }^{32}$. Por otro lado, está el empleo del octosílabo, que resulta significativo en este corpus que desarrolla dicha temática preferentemente en sonetos, adscribiéndose al modelo petrarquista.

Sin embargo, los paralelos más llamativos residen en los mecanismos de inserción: el público de damas principales en un lugar de paso, la admiración y los deseos manifiestos de seguir escuchando esa $v_{0 z}{ }^{33}$, el énfasis en la tierna edad del cantor y de la princesa de Grecia, pero sobre todo la turbación de esta y su nombre: Claribea.

Si bien en la obra de Ortega, a diferencia del episodio del Quijote, no hay aún una relación entre los dos jóvenes en el momento en el que el entonces Doncel de la Aventura canta su nao de amor, esta altera a Claribea, como turba el romance de don Luis a doña Clara ${ }^{34}$. Así, podría plantearse la posibilidad de que este episodio, con su nao inserta, sirviera como inspiración para el episodio del romance de don Luis y que el nombre de la princesa de Grecia le diera pie a Cervantes para escoger el nombre de la hija del oidor y explotarlo poéticamente en el contexto de la navegación amorosa.

\section{CONCLUSIONES}

Cervantes, como transformador de todos los géneros que toca, lo es, como poeta, también de los motivos, aunque ese reconocimiento apenas esté empezando a surgir tímidamente en la tradición crítica.

En las historias del tópico de la navegación amorosa, el lugar que se le ha dado a Cervantes -cuando se menciona- parece ser el de un autor más en el que se registra su uso. Sin embargo, un estudio detenido de estos usos y su contraste con las diferentes tradiciones de las que bebe revela que no estamos ante un corpus que se limite a repetir el motivo, que tenga un valor puramente testimonial, sino ante una variada gama de transformaciones y nuevas posibilidades poéticas que merecen capítulo aparte.

En los recientes estudios de la poesía de Cervantes se ha dado el debate sobre si el análisis de la poesía inserta debe estar siempre anclado al contex-

32. Para las naos de amor ver Sarmati (2009, 69-89).

33. Dorotea dice a doña Clara: «No me digáis nada por ahora, que no quiero perder, por acudir a vuestro sobresalto, el gusto que recibo de oír al que canta» (I, 43 y 448, la cursiva es mía).

34. Recuérdese que, sobre la reacción de doña Clara a la voz de don Luis se dice que «apenas hubo oído dos versos que el que cantaba iba prosiguiendo, cuando le tomó un temblor tan extraño como si de algún grave accidente de cuartana estuviera enferma» (I, 43 y 447). 
to narrativo, o si este enfoque impide apreciar sus méritos per $s e^{35}$. Creo, y he pretendido ponerlo en práctica en este trabajo, que una cosa no excluye la otra. La poesía inserta leída a la luz del marco narrativo se carga de significados que vienen del contexto, y muchas veces es a partir de este que sale a relucir la agudeza y el ingenio del poeta en el empleo y recontextualización de los motivos. En otras ocasiones, su destreza va más allá de estas agudezas 'internas' y lleva a cabo cambios estructurales sobre los sistemas metafóricos que hereda. En ambos casos hay un rico diálogo con la tradición literaria, en ambos reluce la habilidad del poeta en su apropiación y, si bien las obras de los transformadores 'activos' son las que reclaman por derecho propio un lugar en la historia de un tópico, el estudio de ambos tipos de transformaciones redunda en una visión más completa del ingenio poético cervantino en las coordenadas de la lírica de su tiempo.

\section{BIBLIOGRAFÍA CITADA}

Aguilar Perdomo, María del Rosario. 2001. «La nao de amor del Felixmarte de Hircania y otras composiciones líricas en los libros de caballerías peninsulares». Revista de Literatura Medieval 13(2): 9-28.

Alcalá-Galán, Mercedes. 1999. «Teoría de la poesía en Cervantes: poesía citada en la novela». Caliope 5(2): 27-43.

Alcalá-Galán, Mercedes. 2009. Escritura desatada: poéticas de la representación en Cervantes. Alcalá de Henares: Centro de Estudios Cervantinos.

Arellano, Ignacio. 1998. «Visiones y símbolos emblemáticos en la poesía de Cervantes». Anales Cervantinos 34: 169-221. https://doi.org/10.3989/anacervantinos.1998.010

Arellano, Ignacio. 2004. «Elementos emblemáticos en La Galatea y el Persiles». Bulletin of Hispanic Studies 31 (4-5): 571-583.

Ariosto, Ludovico. 2002. Rime, ed. Stefano Bianchi. Milán: BUR Rizzoli Classici.

Armstrong-Roche, Michael. 2011. «Un replanteamiento paradoxográfico de la ortodoxia religiosa, política y social en Cervantes: el mito gótico y el episodio de Sosa y Leonor en el Persiles». En Ortodoxia y heterodoxia en Cervantes, ed. Carmen Rivero Iglesias, 15-32. Alcalá de Henares: Asociación de Cervantistas - Centro de estudios cervantinos.

Avalle-Arce, Juan Bautista. 1975. «Cervantes». En La novela pastoril española, 229-263. Madrid: Istmo.

Bistué Guardiola, Ana María. 1996. «Vistiendo de naufragios los altares: un motivo horaciano en algunos poetas del Siglo de Oro». En Tradició Clàssica. Actes de l’XI simposi de la secció catalana de la SEEC, ed. Mercè Puig Rodríguez-Escalona, 177-184. Andorra: Govern d'Andorra. Ministeri d'Educació, Joventut i Esports.

Blecua, José Manuel. 1970. Sobre la poesía de la Edad de Oro: ensayos y notas eruditas. Madrid: Gredos.

Boscán, Juan. 2010. Obra poética completa. En Los grandes líricos del Renacimiento español, eds. Inoria Pepe Sarno y José María Reyes Cano. Madrid: Cátedra.

Cernuda, Luis. 1964. «Cervantes, poeta». En Poesía y Literatura, II, 45-57. Barcelona: Seix Barral.

35. Ver Olay Valdés (2013). 
Cervantes Saavedra, Miguel de. 1999. La Galatea, eds. Francisco López Estrada y María Teresa López García-Berdoy. Madrid: Cátedra.

Cervantes Saavedra, Miguel de. 2004. Don Quijote de la Mancha, ed. Francisco Rico. San Pablo (Brasil): Real Academia Española - Asociación de Academias de la Lengua Española - Alfaguara.

Cervantes Saavedra, Miguel de. 2004. Los trabajos de Persiles y Sigismunda, ed. Carlos Romero Muñoz. Madrid: Cátedra.

Davis, Elizabeth B. 2004. «La promesa del náufrago: el motivo marinero del ex-voto, de Garcilaso a Quevedo». En Studies in Honor of James O. Crosby, ed. Lía Schwartz, 109-123. Newark: Juan de la Cuesta.

Diego, Gerardo. 1948. «Cervantes y la poesía». Revista de Filología Española 32: 213-236.

Fernández de Navarrete, Martín. 2005. Vida de Miguel de Cervantes. Málaga: Universidad.

Gaos, Vicente. 1979. «Cervantes poeta». En Cervantes. Novelista, dramaturgo, poeta, 159-198. Barcelona: Planeta.

Herrera, Fernando de. 2010. Obra poética completa. En Los grandes líricos del Renacimiento español, eds. Inoria Pepe Sarno y José María Reyes Cano. Madrid: Cátedra.

Lozano-Renieblas, Isabel. 2004. «"Mar sesgo, viento largo, estrella clara” o la metáfora de la nave de amor en el Persiles». Anales Cervantinos 36: 299-308. https://doi. org/10.3989/anacervantinos.2004.010

Manero Sorolla, María Pilar. 1990. Imágenes petrarquistas en la lírica española del Renacimiento. Repertorio. Barcelona: Promociones y Publicaciones Universitarias.

Manero Sorolla, María Pilar. 1991. "Aproximaciones al estudio del petrarquismo en la poesía de Cervantes: la configuración imaginística del amante». En Actas del II Coloquio Internacional de la Asociación de Cervantistas, 755-779. Barcelona: Anthropos.

Mata Induráin, Carlos. 2004. «Algo más sobre Cervantes poeta: a propósito de los sonetos del Persiles». En Peregrinamente peregrinos, Actas del V Congreso Internacional de la Asociación de Cervantistas, ed. Alicia Villar Lecumberri, I, 651-676. s. 1.: Asociación de Cervantistas.

Mata Induráin, Carlos. 2005. «Del amor y la amistad en la primera parte del Quijote. Los sonetos de Cardenio y Lotario». En Actas del XI Coloquio Internacional de la Asociación de Cervantistas, ed. Chul Park, 147-162. Seúl: Universidad Hankuk de Estudios Extranjeros.

Mata Induráin, Carlos. 2007. «Los dos poemas de don Luis (Quijote I, 43) y el tema de la navegación amorosa en la poesía de Cervantes». En Por sendas del Quijote innumerable, ed. Carlos Romero Muñoz, 131-153. Madrid: Visor.

Matas Caballero, Juan. 2016. «La poesía de Cervantes entre tradición y modernidad con Góngora de fondo». Boletín de la Biblioteca Menéndez Pelayo 92: 325-348.

Menéndez Pelayo, Marcelino. 1941. «Cervantes considerado como poeta». En Edición Nacional de las Obras Completas de Menéndez Pelayo. Estudios y discursos de crítica histórica y literaria, eds. Miguel Artigas y Enrique Sánchez Reyes, 1, 257-268. Santander: Aldus.

Micozzi, Patrizia. 1995. «Imágenes metafóricas en la canción a la Virgen de Guadalupe». En Actas del II Congreso Internacional de la Asociación de Cervantistas, ed. Giuseppe Grilli, 721-723. Nápoles: Instituto Universitario Orientale.

Montero Reguera, José. 2011. «Heterodoxias poéticas cervantinas. (Prolegómenos para una edición crítica de la poesía de Cervantes)». En Ortodoxia y heterodoxia en Cervantes, ed. Carmen Rivero Iglesias, 245-271. Alcalá de Henares: Asociación de Cervantistas - Centro de Estudios Cervantinos. 
Montero Reguera, José. 2013. «La poesía. Hacia una nueva edición». En Los textos de Cervantes, ed. Daniel Fernández Rodríguez, 119-163. Madrid: Centro para la Edición de los Clásicos Españoles.

Olay Valdés, Rodrigo. 2013. «Reconsideración de la poesía cervantina: los defectos métricos y estilísticos de Cervantes». Anales Cervantinos 45: 293-324. https://doi. org/10.3989/anacervantinos.2013.012

Ortega, Melchor. 1998. Felixmarte de Hircania, ed. María del Rosario Aguilar Perdomo. Alcalá de Henares: Centro de Estudios Cervantinos.

Petrarca, Francesco. 1989. Cancionero, ed. Jacobo Cortines. Madrid: Cátedra, 2 vols.

Ramajo Caño, Antonio. 2001. «La execración de la navegación, el navigum amoris y el propempticón en la lírica áurea». Boletín de la Real Academia Española LXXXI(CCLXXXII): 507-528.

Rojas, Ricardo. 1948. Cervantes. Buenos Aires: Losada.

Romo Feito, Fernando. 2001. «Cervantes ante la palabra lírica». En Volver a Cervantes. Actas del IV Congreso Internacional de la Asociación de Cervantistas, ed. Antonio Bernat Vistarini, II, 1063-1088. Palma: Universitat de les Illes Balears.

Romo Feito, Fernando. 2011. «Nota para el tema 'Cervantes, mal poeta'». En Leyendas negras e leggende auree, ed. Maria Grazia Profeti y Donatella Pini, 147-152. Florencia: Alinea Editrice.

Romo Feito, Fernando. 2012. «Cervantes ante la palabra lírica: el Quijote». Anales Cervantinos 44: 133-158. https://doi.org/10.3989/anacervantinos.2012.007

Ruiz Pérez, Pedro. 1997. «Contexto crítico de la poesía cervantina». Cervantes 17(1): 62-86.

Sánchez, Alberto. 1985. «Los sonetos de La Galatea». En La Galatea de Cervantes: cuatrocientos años después, ed. Juan Bautista Avalle-Arce, 19-36. Newark: Juan de la Cuesta.

Santa-Aguilar, Sara. 2015. «La poesía en la ficción: una aproximación a la estructura de "El curioso impertinente"». Hipogrifo. Revista de literatura y cultura del Siglo de Oro 3(2): 285-295.

Santa-Aguilar, Sara. 2018a. «Elicio, Erastro y Galatea en clave poética». Criticón 133: $37-56$.

Santa-Aguilar, Sara. 2018b. «La Galatea y las expectativas de una tradición literaria: el caso de Teolinda». Hipogrifo. Revista de literatura y cultura del Siglo de Oro 6(2): 283-295.

Sarmati, Elisabetta. 2009. Naufragi e tempeste d'amore. Storia di una metafora nella Spagna dei Secoli d'Oro. Roma: Carocci editore.

Trabado Cabado, José Manuel. 2000. Poética y pragmática del discurso lírico. El cancionero pastoril de La Galatea. Madrid: CSIC.

Vega, Garcilaso de la. 2013. Poesías castellanas completas, ed. Elías L. Rivers. Madrid: Castalia.

Zimic, Stanislav. 2003. Los cuentos y las novelas del Quijote. Madrid - Barcelona: Iberoamericana - Vervuert.

Zimic, Stanislav. 2005. Cuentos y episodios del Persiles: de la isla bárbara a una apoteosis del amor humano. Pontevedra: Mirabel.

Recibido: 1 de abril de 2020

Aceptado: 14 de julio de 2020 
